\section{Edycaçä́a

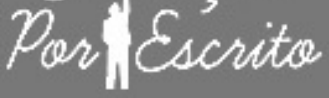

ARTIGO

\section{Editor}

Maria Inês Côrte Vitoria PUCRS, RS, Brasil

\section{Editor Executivo}

Pricila Kohls dos Santos PUCRS, RS, Brasil

\section{Equipe Editorial}

Rosa Maria Rigo

PUCRS, RS, Brasil

Carla Spagnolo

PUCRS, RS, Brasil

Martha Luci Sozo

PUCRS, RS, Brasil

Dirce Hechler Herbertz

PUCRS, RS, Brasil

\section{ISSN 2179-8435}

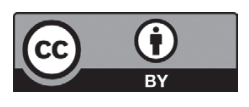

Este artigo está licenciado sob forma de uma licenç Creative Commons Atribuição 4.0 Internacional, que permite uso irrestrito, distribuiçăa e reproduçâa seja corretamente citad http://creativecommons.org/licenses/by/4.0/deed.pt BP

\title{
O ensino da arte no Colégio Pedro II: resistência e mudança
}

\author{
The art education at Colégio Pedro II: resistance and change
}

\author{
Maria do Carmo Potsch de Carvalho e Silva ${ }^{a}$ \\ Laélia Portela Moreira ${ }^{b}$
}

RESUMO: O artigo apresenta uma análise crítica da trajetória do ensino da arte no Colégio Pedro II (CPII), do ensino do Desenho à atual disciplina Artes Visuais. Buscou-se relacionar as tendências nacionais e internacionais às políticas e às práticas do ensino dessa disciplina no CPII, em suas diversas fases e modalidades. A metodologia incluiu estudo de documentos e entrevistas com professores e ex-professores. Após breves anotações sobre o ensino da arte, detalha-se a trajetória da disciplina, a partir da análise de conteúdo da documentação e das entrevistas realizadas. Os resultados mostram que as diversas fases e denominações apresentadas pelo ensino da arte, nesse educandário, refletiram as políticas nacionais, influenciadas pelas tendências internacionais, e também que seus professores influenciaram as políticas e a formulação dos conteúdos dessa disciplina por meio de sua ação pedagógica e política.

Palavras chave: Colégio Pedro II; ensino da arte; arte/educação.

ABSTRACT: The article presents a critical analysis of the trajectory of art education at Colegio Pedro II (CPII), from the teaching of drawing to the current subject Visual Arts. The research sought to relate trends in national and international policies and practices of the teaching of this discipline in CPII, in its various forms and stages. The study methodology included documents and interviews with teachers and former teachers. After consideration about the teaching of art, details the history of the discipline at CPII, from the content analysis of documentation and interviews. The results show that the different phases and names submitted by the teaching of art in this breed, reflected national policies, influenced by international trends, as well as their teachers proposed programs, policies and influence the formulation of contents this discipline through its political and pedagogical action.

Keywords: Pedro II College; teaching art; art/education.

\footnotetext{
a Mestre em Educação pelo Programa de Pós-Graduação em Educação da Universidade Estácio de Sá, PPGE/UNESA. Graduada em Educação Artística pelo Instituto Metodista Bennett e em Psicologia pela Universidade Santa Úrsula, no Rio de Janeiro. Professora de Artes Visuais do Colégio Pedro II, Unidade Humaitá, Rio de Janeiro.

b Doutora em Educação pela Universidade Federal do Rio de Janeiro (UFRJ). Mestre em Educação pelo IESAE/FGV, Rio de Janeiro. Professora e Pesquisadora do Programa de Pós-Graduação em Educação da Universidade Estácio de Sá (PPGE/ UNESA), no Rio de Janeiro. Linha de Pesquisa: Políticas, Gestão e Formação de Educadores (PGFE).
} 


\section{Introdução}

ensino escolar da arte teve início nos primeiros Liceus secundários que surgiram no começo do século XIX, escolas que inspiraram, no Brasil, a criação do Imperial Colégio de Pedro II (CP II). A trajetória dessa disciplina tem sido marcada por várias fases que expressaram diferentes tendências e metodologias, inspiradas pelos interesses políticos e educacionais de cada época. No Brasil, o ensino da arte careceu de políticas consistentes até recentemente, fato que causou problemas na definição da disciplina e acarretou dificuldades relacionadas à sua inclusão nas matrizes escolares, ao seu reconhecimento pela comunidade escolar e à formação de professores.

O CP II foi criado em um contexto de esforço de organização do ensino secundário na capital do Império e nas províncias, tendo como um de seus objetivos servir de parâmetro para as demais escolas da época. Fundado em 2 de Dezembro de 1837 pelo Ministro do Império Bernardo Pereira de Vasconcelos e batizado originalmente como Imperial Colégio de Pedro II, em homenagem ao jovem Imperador, foi uma das primeiras providências governamentais brasileiras para a organização do ensino secundário, à época caracterizado por iniciativas particulares, principalmente orientadas para o acesso às faculdades recém-criadas, nos chamados cursos preparatórios. Todos os movimentos da legislação do período Imperial no tocante ao ensino secundário guardam relação direta com esta escola.

Exposto às forças evolutivas da sociedade, o CP II exerceu influência e também foi influenciado por elas, passando, desde sua instituição, por transformações correspondentes aos diferentes períodos e ideologias. A longevidade desta instituição, sua importância histórica e a manutenção de padrões elevados de ensino a tem tornado objeto de interesse crescente e de estudos acadêmicos realizados por pesquisadores de diversos campos e temáticas.

Com o objetivo de preservar importante capítulo do ensino da arte no Brasil, a partir de sua estruturação e desenvolvimento no CP II, a pesquisa que apresentamos neste artigo busca contribuir para a construção da memória desse educandário. Esse esforço de recuperação da história da disciplina que recebe atualmente a denominação de "Artes Visuais" visa também ao fortalecimento do Núcleo de Documentação e Memória do Colégio Pedro II (NUDOM)1, já existente, cujo acervo contém documentos administrativos com os registros dos atos praticados pela instituição desde a sua fundação em 1837.

A investigação incluiu análise de documentos do Colégio e entrevistas. No que se refere à parte documental, contamos com o acesso ao Fundo Colégio Pedro II, localizado no NUDOM, e ao acervo reunido por uma das

\footnotetext{
1 O NUDOM foi criado em 1995, com o objetivo de resgatar e organizar tecnicamente o acervo documental do CP II, formalizando o movimento iniciado em 1990 pelo professor de História e ex-aluno Geraldo Pinto Vieira e pela professora Vera Maria Ferreira Rodrigues, então diretora da Unidade Centro.
} 
professoras entrevistadas. Foi analisada a seguinte documentação: Legislação dirigida ao ensino da arte do período imperial e da República; Avisos do Império; Anuários do Colégio Pedro II; Regimentos do Colégio Pedro II; DecretosLei; Portarias Ministeriais; Planos Gerais de Estudos (PGEs) da disciplina Educação Artística; relatórios de cursos de reciclagem de professores e carta dos professores à direção da Instituição.

As entrevistas abrangeram especialmente o período compreendido entre o ano de 1943, quando aconteceu a mudança da denominação Desenho para Trabalhos Manuais, e o período imediatamente após a promulgação da Lei de Diretrizes e Bases da Educação Nacional, Lei 9.394/96, quando o ensino da arte recebe a denominação "Artes Visuais". Foram entrevistados 18 professores, quatro dos quais também ex-alunos, selecionados com base nos seguintes critérios: (a) serem detentores de informações não encontradas total ou parcialmente nos documentos; (b) terem sido alunos e/ou professores de arte do Colégio; e (c) por trabalharem ou terem trabalhado com a disciplina, nesse estabelecimento, em diferentes décadas.

Após breve introdução sobre os primórdios do ensino da arte no Brasil, apresenta-se, na sequência, uma análise das diversas fases desse ensino: do Desenho até o período em que a disciplina recebe a denominação "Artes Visuais", após a promulgação da Lei 9.394/96.

\section{Trajetória do ensino da arte no Brasil e suas repercussões no Colégio Pedro II}

Do início da colonização portuguesa aos dias de hoje, o ensino da arte, no Brasil, percorreu uma longa trajetória, com enfoques que se desenvolveram de acordo com os interesses políticos e econômicos de cada época. Sua primeira manifestação formal aparece já no começo da colonização portuguesa, pela ação dos religiosos jesuítas que realizaram o trabalho de transposição da cultura europeia para a nova colônia, trazendo hábitos, religião, leis e a própria arte, impondo-os aos povos indígenas, aos negros e mestiços, além de educar os colonos e a seus filhos.

A Reforma Pombalina, iniciada em 1759 com o objetivo de promover uma renovação metodológica que abrangeria as Ciências, as Artes Manuais e a Técnica, teve como resultado imediato a expulsão dos jesuítas e o desmantelamento de parte da estrutura administrativa de seu sistema de ensino, com a substituição da uniformidade de sua ação pedagógica pela diversificação das disciplinas isoladas. Apesar das dificuldades criadas, essa reforma permitiu um novo posicionamento para o ensino da arte, tendo como uma das primeiras consequências a inclusão do desenho no currículo do Seminário Episcopal de Olinda, além da introdução das aulas régias² (BARBOSA, 2005).

2 Em 1800 foi criada uma aula régia de desenho e figura, regida por Manoel Dias de Oliveira, O Manoel Brasiliense, com a introdução do modelo vivo no ensino. 
Para Barbosa (1998), a contratação do grupo que ficou conhecido como a Missão Artística Francesa, organizado por Joachim Lebreton e formado por neoclássicos convictos, interferiu ostensivamente na mudança de paradigma estético no Brasil, criando uma escola neoclássica de linhas retas e puras, contrastando com a abundância de movimentos do nosso barroco. Segundo esta autora, D. João VI transpôs para o Brasil o hábito das cortes europeias de incluir as artes na educação dos príncipes, como símbolo de distinção e refinamento. $\mathrm{O}$ desenvolvimento da arte barroca, a arte brasileira e popular foi interrompido, passando a Academia de Belas Artes a ser o centro de referência para os jovens vocacionados para a arte. O estilo neoclássico torna-se a base curricular do ensino de Belas-Artes, acarretando um grande distanciamento entre a arte acadêmica e a popular. A partir dessa época consolida-se o ensino do desenho, caracterizando o segundo momento no ensino da arte no Brasil, relacionado com as necessidades de modernização e industrialização, ocorridas após a chegada da corte portuguesa em 1808 e ao posterior desencadeamento do processo de independência.

\section{0 ensino da arte como ensino de Desenho}

O ensino do desenho como cópia do real, com o uso de estampas e modelos da natureza ou mesmo modelos vivos e do desenho geométrico foi característico dos tempos iniciados pela revolução industrial. Nesse momento, o fazer e o conhecer determinaram um ensino com pouca liberdade de expressão, com o objetivo de educar para o trabalho, embora incluísse a intenção de ensinar a arte para todos, rompendo com a concepção elitista dominante. $\mathrm{O}$ ensino de Trabalhos Manuais, instituído a partir de 1942, também guarda relação com este ideário.

A partir da década de 30 do século XIX apareceram, segundo Xavier (1994), os primeiros currículos seriados nas províncias, logo uniformizados pelo modelo que viria a se formar com a criação do Colégio Pedro II, em 1837, no Rio de Janeiro. O primeiro professor da disciplina Desenho foi Araújo Porto Alegre, escritor, político, pintor de formação acadêmica e caricaturista. Aluno de Debret na Imperial Academia de Belas Artes, lecionou no CP II por cerca de um ano e posteriormente dirigiu a Imperial Academia de Belas Artes, tendo promovido uma das tentativas de modernização desta instituição que então mantinha um ensino da arte considerado elitista e excessivamente acadêmico (DORIA, 1997).

Sendo o Imperial Colégio de Pedro II a instituição parâmetro para a ordenação do ensino secundário no país, questões como a obrigatoriedade do ensino do Desenho em todos os anos de estudo, a exemplo do que havia sido então recentemente instituído na França e a proposta de contratação de professores europeus para esta disciplina, como ocorrera nos Estados Unidos, foram levantadas. A influência das metodologias oriundas dos diferentes modos de pensar sobre o ensino da arte está registrada nos programas do Colégio. ${ }^{3}$

3 Para a obtenção de detalhes sobre estes programas, consultar Carvalho e Silva (2013) onde foram detalhados os programas dos anos de 1878 , $1882,1850,1892$ e 1893.

Educação Por Escrito, Porto Alegre, v. 7, n. 1, p. 88-105, jan.-jun. 2016 
Os programas da disciplina permitem compreender a natureza do ensino proposto, bem como os conteúdos ministrados e os livros adotados. O ensino do desenho geométrico, presente no programa de 1878, estava relacionado com as aplicações na indústria, em projetos nos quais o raciocínio preciso e matemático era necessário. Expressa a tentativa de fazer com que a arte tivesse uma aplicação prática na vida das pessoas, oferecendo a possibilidade de um ofício, embora este não fosse o objetivo principal do CP II.

O caráter acadêmico do ensino do Desenho no CP II, como reprodução de formas ideais e treinamento da vista e da mão, foi dominante em relação à livre expressão e à arte moderna, por muitas décadas. A dimensão expressiva passou a ser considerada de modo mais consistente apenas a partir do início da década de 1970, quando a reformulação do ensino imposta pela Lei 5.692/71 determinou, pela primeira vez na história, a obrigatoriedade do ensino da arte nas escolas, com a denominação Educação Artística.

O ensino da arte como Desenho esteve presente durante todo o período imperial e parte da República e segue até o ano de 1942, quando ocorre uma mudança de sentido: a disciplina de Desenho continua a existir como desenho geométrico e de figura, porém, o ensino da arte passa a ser considerado como o ensino de Trabalhos Manuais, que representa a sua segunda denominação. ${ }^{4}$

\section{O ensino da arte como Trabalhos Manuais}

O treinamento manual como parte da educação geral foi proposto nos Estados Unidos por John Runkle, presidente do Massachusets Institute of Technology, no ano de 1876. Inspirado por uma exibição da Escola Técnica Imperial de Moscou realizada na exposição Philadelphia Centennial, Runkle apresentava, com uma série de exercícios, o treinamento manual como modo de fornecer disciplina mental adequada para todas as crianças e preparar os estudantes para acessar algumas áreas da indústria (EFLAND, 1990). Nessa perspectiva, o treinamento manual educaria a mente através da mão e ensinaria valores morais como precisão, lógica, diligência e economia. Segundo Segismundo (1939), Runkle teria sido o primeiro a perceber que tal tipo de instrução continha elementos de valor para um plano geral de educação.

De acordo com Efland (1990), Os trabalhos manuais em madeira foram propostos por Otto Salomon no método denominado Sloyd, que teve origem no norte da Suécia, onde as longas noites de inverno impediam os trabalhos nos campos e pradarias, fazendo com que os camponeses realizassem tarefas em seus próprios lares. Os homens confeccionavam ancinhos, partes de instrumentos, colheres de madeira, bancos, mesas e outros artigos de necessidade

\footnotetext{
4 A disciplina Desenho foi mantida no CP II até a atualidade, com programas relacionados com os existentes naquele momento em que
} Trabalhos Manuais passou a ser a denominação para o ensino da Arte. 
nas casas e nas granjas. As mulheres faziam bordados e rendas. Posteriormente o Sloyd foi incluído nas escolas, por suas vantagens educativas.

Quanto ao trabalho manual escolar, segundo Vasconcelos Junior (1900, apud SEGISMUNDO, 1939), consistia, no Brasil, em uma série de manipulações em papel, cartão, argila, gesso, madeira e metal, no momento em que o ensino dessa disciplina era vinculado apenas ao primário. Fonseca (apud SEGISMUNDO, 1939) afirma que o objetivo dos trabalhos manuais é tornar o ensino mais eficiente, auxiliando a criança na confecção de coisas de sua necessidade e facilitando a transmissão de conhecimentos por meio dos sentidos e pela atividade da mão.

Segismundo (1939) informa que a crescente atenção para com os trabalhos manuais levou à sua aplicação por educadores como Anísio Teixeira e Fernando de Azevedo, respectivamente, nas escolas da Bahia, em 1924, e no Distrito Federal, em 1927 e à obrigatoriedade de seu ensino, decretada pela Constituição de 1937, no Art. 131, nas escolas primárias, normais e secundárias, juntamente com a educação física e o ensino cívico. $\mathrm{O}$ ensino de trabalhos manuais teria criado uma didática viva e atrativa, que prepararia para a vida, e estaria ligado organicamente a todas as disciplinas, segundo os princípios da Escola Nova.

No CP II essa disciplina foi instituída efetivamente no ano de 1943, determinada pelo Decreto-Lei no 4.244 de abril de 1942, com programas posteriormente expedidos pela Portaria Ministerial no 557, de novembro de 1945. O Art. 11 da Lei $\mathrm{n}$ o 4.244 trata da seriação das disciplinas e localiza o ensino de Trabalhos Manuais nas duas primeiras séries do ginásio, juntamente com Desenho e Canto Orfeônico, no item Artes. Nas duas últimas séries, seguem apenas Desenho e Canto Orfeônico. Na terceira e quarta séries, o Título III, que enfoca o ensino secundário feminino, determina a inclusão da disciplina Economia Doméstica, no conjunto de uma orientação metodológica geral que afirma considerar a natureza da personalidade feminina e a missão da mulher no lar (BRASIL, 1942)

Pelo disposto na referida Lei, vê-se que o ensino de Trabalhos Manuais era entendido como parte do ensino das Artes e sua associação com o ensino de Economia Doméstica, que fornecia instrução nas questões concernentes à administração do lar e ao manejo nos problemas práticos diários, ocorreu para atender às crescentes matrículas de meninas nas escolas, processo iniciado no final da década de 1920. A Professora N, admitida no colégio Pedro II no ano de 1957, faz referência às disciplinas: "É, lá então naquela época era assim, Trabalhos Manuais e Economia Doméstica, e aí eu fiquei dando aula das duas disciplinas, né? Eu tinha duas matrículas".

Sobre o programa de Economia Doméstica, esclarece a entrevistada N:

“Ah! Lembrei! Tinha aula de etiqueta, era para meninas. Elas aprendiam a servir a mesa à francesa, a como se apresentar na sociedade, como arrumar uma mesa. Tinha uma professora que dava umas aulas práticas. Então levava um faqueiro de prata, taças, um monte de coisas e as alunas tinham que mostrar o que tinham aprendido (risos). Hoje em dia tem umas escolas que oferecem essas aulas, extra. Como Receber. Ah! Tinha até um livro de etiqueta.”

Educação Por Escrito, Porto Alegre, v. 7, n. 1, p. 88-105, jan.-jun. 2016 
Os programas para o ensino da arte ministrado no CP II, assim como os das demais disciplinas, deveriam ser seguidos por todas as escolas de ensino secundário do país. Este lugar de parâmetro encontra-se explícito na legislação correspondente $^{5}$, que confere à Congregação do Colégio a prerrogativa de elaborar os programas das disciplinas lecionadas nesse educandário. A Portaria no 614 do Ministério de Estado da Educação e Saúde, de 10 de maio de 1951, determina que os programas das disciplinas lecionadas no CP II serão elaborados pela sua Congregação e expedidos pelo Ministro da Educação e Saúde para adoção por todos os estabelecimentos de ensino secundário do país (BRASIL, 1951).

As Instruções Metodológicas (BRASIL,1945) estabelecem que o ensino de Trabalhos Manuais no ensino secundário não tem objetivos profissionais, mas essencialmente educativos, baseados: (a) no trabalho com as coisas, que possibilitaria aos adolescentes entrar em contato com a objetividade e o realismo do mundo adulto; (b) no trabalho como fonte de satisfação intelectual e de exercício do bom gosto. Quanto aos materiais, deveriam ser utilizados a madeira, o metal e a massa plástica.

O relato da professora $\mathrm{N}$ permite ilustrar o ensino de Trabalhos Manuais, de acordo com o programa:

“Trabalhos Manuais era assim, tinha trabalho de madeira, trabalho em metal e trabalho de couro [...] então era assim, bem determinado. Tinha aquele programa certo, marcador de livro de madeira, de metal (risos). Aí tinha a serrinha tico-tico... lixa pra metal [...] depois a gente foi introduzindo o artesanato... essa época... Tinha também bordadinho... alguma coisa assim de rococó... mas aí já era Economia Doméstica... época em que... antes da Educação Artística, era mais de artesanato."

Os parâmetros apresentados na proposta de programa para a disciplina Trabalhos Manuais são consistentes com as propostas de Runkle e Woodward, já mencionadas (EFLAND, 1990). Do ponto de vista teórico, trata-se da arte entendida como fazer e como conhecer, de acordo com Pareyson (2001). De um fazer com arte e não propriamente do fazer arte. Não teria a relevância da arte acadêmica ${ }^{6}$. Isto talvez explique o preconceito dirigido a esta disciplina ao longo do tempo, embora as Instruções Metodológicas de Trabalhos Manuais ${ }^{7}$ (BRASIL, 1945) abordem a questão do respeito pelas profissões manuais e artísticas.

5 Para detalhes relacionados à legislação, consultar Carvalho e Silva (2013).

${ }^{6}$ Nesse ponto vale lembrar as observações de Gombrich (1999), para quem não existe nada a que se possa atribuir realmente o nome arte, havendo apenas artistas. Em sua concepção, é possível atribuir o nome arte a diferentes atividades humanas. A palavra "arte" pode significar coisas diferentes, em épocas e lugares diferentes, não havendo problema na atribuição dessa palavra a uma atividade considerada mais simples. Não existiria, assim, arte com A maiúsculo, conceito que teria se transformado em um tipo de fetiche.

7 Expedidas pela Portaria no 557 de 1945. 
No CP II, a existência desse preconceito, que os legisladores pensaram evitar, aparece tanto no relacionamento com os demais professores quanto com a própria instituição, conforme os depoimentos das professoras $\mathrm{Y}$ e $\mathrm{N}$, que ingressaram no Colégio com formação Normal, para o magistério na disciplina de Trabalhos Manuais. Y relata que os professores das demais disciplinas eram convidados anualmente para as exposições promovidas pelas professoras de Trabalhos Manuais, porém jamais comparecendo. O depoimento dessa professora permite compreender o longo esforço para manter posição em um contexto desfavorável:

“[...] nós fazíamos os trabalhos, mas só ia ver a exposição quem? Os pais é que iam. A gente fazia sempre no fim do ano. Mas era difícil um diretor geral se dignar a sair da sua pompa e circunstância ... para inaugurar uma exposição... Eram todos catedráticos, olha a distância que tinha de uma professora de Artes, de Trabalhos Manuais, para um catedrático de renome no Rio de Janeiro.”

As Instruções Metodológicas de Trabalhos Manuais (BRASIL, 1945) mencionam também que muitos exercícios deverão estar relacionados com lições de outras disciplinas e os projetos poderão ser combinados com os outros professores. Segue a professora Y: "Eu fazia mapa! Eu fazia quebra-cabeça de mapa para criança, coloria e depois passava a serrinha tico-tico e dividia os estados brasileiros para fazer um joguinho. Será que nós não estávamos ajudando à Geografia?".

Segismundo (1939) entende que os Trabalhos Manuais constituem a disciplina de integração e unicidade da educação, intervindo em quase todas as outras, melhorando-as e completando-as. Seria também uma resposta à tendência à elitização na educação favorecendo a compreensão, por parte dos alunos, de que não existiriam diferenças entre eles, pobres ou ricos, pretos ou brancos, todos eles brasileiros, sendo preparados pelos mesmos professores e processos para a vida individual e coletiva.

As palavras da professora Y ligam a realidade do ensino do CP II a esses aspectos previstos pelos propositores do ensino dos Trabalhos Manuais.

"Então eu via nas colegas um mérito enorme, por que elas pegavam aquelas crianças... crianças que precisavam de dinheiro... que produziam artesanalmente para vender em feiras hippies que estavam começando a surgir, para vender para os familiares, ou o patrão do pai, o patrão da mãe, entendeu?... vendiam para os próprios professores e faziam uma fonte de renda daquilo, muito bonita até." 
Trabalhos Manuais (com a inclusão de Economia Doméstica) permaneceu como disciplina relacionada com o ensino da arte até o ano de 1971, quando foi extinta pela Lei 5.692/71, que determinava, pela primeira vez no Brasil, a obrigatoriedade do ensino escolar da arte com a denominação Educação Artística.

\section{Do Ensino da Educação Artística à Constituição da Disciplina "Arte"}

As mudanças no campo do ensino escolar da arte a partir de 1971, com a promulgação da Lei 5.692/1971, aconteceriam no contexto mais amplo da reforma educacional levada a cabo pelo governo militar, instaurado a partir de 1964. A percepção do significado da educação para o desenvolvimento aconteceu desde o início por parte do novo regime e o aumento da demanda da sociedade por educação evidenciou as antigas e permanentes deficiências do sistema educacional, bem como a necessidade de medidas concretas para ajustar o sistema educacional ao modelo de desenvolvimento econômico que se intensificava no Brasil (ROMANELLI, 2010).

Para atingir tais objetivos, a Lei 5.692/71 promoveu mudanças na estrutura do ensino, ampliando a obrigatoriedade escolar para 8 anos, na faixa etária dos 7 aos 14 anos. Esta intervenção aumentou a obrigação do Estado em relação à educação do povo e implicou uma mudança profunda na educação elementar. $\mathrm{O}$ ensino da arte foi incluído no currículo pelo Art. 7º, que dispõe sobre as matérias obrigatórias Educação Moral e Cívica, Educação Física, Educação Artística e Programas de Saúde (BRASIL, 1971)

Para Barbosa (2005a), a obrigatoriedade das artes nas escolas de 1으 e $2^{\mathrm{O}}$ graus foi uma criação ideológica dos educadores norte-americanos que reformularam a educação brasileira através dos acordos MEC-USAID, estabelecendo os objetivos e o currículo apresentados na Lei 5.692/1971. Esta Lei determinou uma educação tecnologicamente orientada, iniciando a profissionalização da criança a partir da $7 \underline{a}$ série e tornando o ensino do $2^{\mathrm{o}}$ grau totalmente profissionalizante. As artes ficaram como a única disciplina ligada às humanidades e à criatividade, em um currículo do qual foram retiradas Filosofia e História.

A Lei 5.692/1971 determinou a existência de Educação Artística como atividade nas primeiras séries do primeiro Grau, área de estudo nas últimas séries, e disciplina no segundo Grau, segundo Rosa (2005). O Parecer no 853/1971 do Conselho Federal de Educação (BRASIL, 1971) faz a distinção entre atividade, área de estudo e disciplina: na atividade, o aprendizado é desenvolvido em experiências obtidas em situações concretas, principalmente, ficando a apresentação sistemática dos conhecimentos em segundo plano; nas áreas de estudo, formadas pela integração de conteúdos afins, há um equilíbrio entre as situações de experiência e estudos sistemáticos e, finalmente, nas disciplinas, as mais específicas, o aprendizado acontece predominantemente sobre conhecimentos sistemáticos.

O conceito de prática educativa, que abrangia a disciplina de Trabalhos Manuais na legislação anterior, foi abandonado, ficando incluído em atividade. Esclarece o parecer que a progressão de atividade a área de estudo e 
disciplina está relacionada com o amadurecimento da criança, que passa por diferentes níveis de capacidade de compreensão e sistematização. Logo, um campo do saber pode ser atividade no início da escolarização, área de estudo no período intermediário e disciplina no tempo mais avançado.

A reforma educacional de 1971 determinou a prática da polivalência como um novo conceito de ensino da arte (BARBOSA, 2008). As artes plásticas, a música e as artes cênicas deveriam ser ensinadas conjuntamente e por um mesmo professor, da $1^{\underline{a}}$ a $8^{\underline{a}}$ séries do 10 grau. A autora salienta que Educação Artística foi a denominação que passou a designar o ensino polivalente de artes plásticas, música e teatro. Barbosa (2005b) critica severamente a polivalência proposta pela nova lei e o tempo exíguo estabelecido para a formação dos novos professores.

O CP II iniciou sua movimentação em relação à Lei 5.692/1971 quando reuniu seu Conselho Departamental em janeiro de 1972 com o objetivo de levar ao Colegiado as normas, advindas da Lei, recém-aprovadas pelo Conselho Federal de Educação. O Conselho designou duas comissões com a incumbência de elaborar os currículos que passariam a ser aplicados, já no ano de 1972, a partir da $1^{a} \underline{a}$ série do $2^{\circ}$ grau, procurando demonstrar presteza em atender às orientações do governo. Estes novos currículos tiveram que ser adaptados com o objetivo de contornar as consequências da acentuada redução das horas semanais direcionadas às disciplinas consideradas de "Educação Geral", aplicada para a introdução das chamadas disciplinas profissionalizantes, com carga horária semanal maior. A leitura do Plano Global de Implantação Progressiva das Habilitações Básicas deixa clara a falta de condições materiais para implantação do ensino profissionalizante e, ao mesmo tempo, a tensão entre essa exigência e a tradição humanística da Instituição. Foram selecionadas, como habilitações básicas: Construção Civil; Eletricidade; Eletrônica; Mecânica; Saúde e Artes. A implantação da Habilitação Básica de Artes foi postergada por indefinição legal (BRASIL, 1977).

A Educação Artística trouxe a proposta de estímulo à criatividade, mas o aspecto do laissez-faire, o livre fazer muito vinculado à livre expressão artística, não cabia em uma tradição de organização e planificação como a do CP II, e não aconteceu. A polivalência foi outro aspecto da Lei 5.692/1971 que segundo todos os professores entrevistados não teve repercussão neste educandário. A professora $\mathrm{Y}$ fornece explicações para este fato:

\footnotetext{
"Não (houve polivalência) porque o Pedro II tinha um coral maravilhoso... ouvido longe, em tudo quanto era solenidade... a música tinha um lugar privilegiado... ela acompanhava todas as solenidades do Pedro II... a música tinha um papel já garantido... educação musical, a educação artística, o campo visual todo e as danças ... E como é que fica o professor polivalente que tinha que dar essas disciplinas, que eram consideradas artes? Isto eu acho que foi um erro, realmente."
} 
No CP II, os professores procuravam adaptar-se às novas exigências. A existência de uma equipe capacitada em Trabalhos Manuais, desde o ano de 1943, explica o direcionamento para as Artes Plásticas, o que consideramos natural para aquele grupo de professores. A professora $\mathrm{N}$ explica a transição:

“Até que veio a mudança... ai então a matéria ... passou a se chamar Educação Artística, né? É, acho que depois Artes Plásticas, mas primeiro foi Educação Artística, né? ... a gente procurava trabalho, pintura, mas é... não era muito... vamos dizer assim, programa. A gente que, quando chegava no princípio do ano, a gente reunia, mais ou menos... um programa dentro do esquema que era pedido, aí fazia a... os trabalhos que iam ser dados e tudo."

A busca dos professores por embasamento técnico e teórico aparece em registros de observações e sugestões quanto aos recursos humanos, incluídas no Programa de Educação Artística - Artes Plásticas da Unidade Bernardo de Vasconcelos, seção Tijuca (COLÉGIO PEDRO II, 1979). Adaptados a uma tradição de programas bem definidos, os professores do Colégio estavam agora diante de uma nova disciplina, que propunha estimular a criatividade, no âmbito de uma polivalência que não fazia sentido para eles. A resposta deste corpo docente foi buscar a formação que considerava necessária, como explica a Profa. N, fazendo referência a uma professora da equipe de arte do CP II e a uma artista plástica que ministrava aulas no Museu de Arte Moderna (MAM).

“[...] ela começou a dar aula pro grupo e a gente começou a montar um programa já muito diferente do que a gente fazia, entendeu? Levando o aluno a observar um trabalho e daquele trabalho fazia um outro em cima... repintando, recriando... a gente fez isso, fez colagem... a Carli mostrando... livros de pintores famosos que faziam aquele tipo de trabalho..."

A busca por novos conhecimentos levaria este grupo de professoras, formadas pela Escola Normal em Trabalhos Manuais e Economia Doméstica, a realizar um salto teórico e técnico em direção às artes plásticas. Passaram a ter acesso a trabalhos de autores que despontavam na época com propostas inovadoras, entre eles a arte-educadora Ana Mae Barbosa, e adotaram práticas como a visitação a museus, em acordo com as novas propostas da Educação Artística. $\mathrm{O}$ Projeto de Dinamização do Ensino de Educação Artística apresenta como objetivos gerais ${ }^{8}$ de Artes Plásticas:

Desenvolver no educando a capacidade de criar e expressar-se através da arte. Incentivar a apreciação crítica, a criação e preservação dos valores sócio-econômico-culturais.[...] Promover o conhecimento das possibilidades profissionais que as artes plásticas oferecem (COLÉGIO PEDRO II, 1979, p. 1).

8 Para detalhes, ver Carvalho e Silva (2013). 
Nesse projeto, identificam-se, entre outros, elementos como a contextualização histórica, relacionados com as propostas de Ana Mae Barbosa para o ensino da arte, no que posteriormente iria configurar a Proposta Triangular. O depoimento da professora Y fornece uma dimensão da situação do ensino da arte no CP II naquele momento, em comparação com outras escolas:

\footnotetext{
"Quando a Ana Mae Barbosa conseguiu projetar as Artes Visuais e a Educação Artística... eu levei os professores todos do Departamento pra assistir a uma reunião na UERJ. Quando eu comecei a falar, elas (professoras de outros estabelecimentos) pensaram que era outro assunto que nós estávamos falando... Nós já estávamos num estágio tão adiantado no Pedro Segundo, que Ana Mae Barbosa e outras inúmeras eram o nosso cotidiano há muito tempo, e elas não tinham nem entrado nisso, ainda."
}

Outra orientação do Programa de Educação Artística proposta para o 2o Grau (COLÉGIO PEDRO II, 1979) é que fosse oferecida uma oportunidade especial aos alunos que mostrassem inclinação particular para as artes, com a realização de atividades artísticas paralelas às curriculares, durante os três anos desse segmento. Quanto a este aspecto, a iniciativa da professora $\mathrm{Y}$ criou um trabalho que permanece até a atualidade, na forma do Curso de Habilidade Específica direcionado aos vestibulares.

O ensino da arte no CP II seguia seu curso, nesse tempo muito determinado pelas iniciativas de seus professores. No campo administrativo, os programas de ensino passam a constar, a partir de 1981 e para todas as disciplinas, nos Planos Gerais de Ensino (PGEs). Os PGEs organizaram os programas de Educação Artística por 16 anos e contêm o registro da evolução da disciplina ao longo desse tempo. Permaneceram em vigor de 1981 a 1996. A Educação Artística estava relacionada nos PGEs de 1981 e 1982 junto com Educação Física e Educação Musical. O conteúdo da disciplina Educação Artística é programado com objetivos específicos por unidade didática, estratégia didáticopedagógica e bibliografia. Ficam esboçados nos programas de Artes Plásticas, já no início dos anos 1980, as mudanças cruciais que tomariam corpo ao longo daquela década no ensino da arte e que viriam a ser adotadas pelos Parâmetros Curriculares Nacionais (PCN), de 1997, com a junção das vertentes definidoras da arte como fazer, conhecer e expressar (COLÉGIO PEDRO II, 1981).

Uma crise é iniciada no ano de 1985, momento em que o PGE restringe o ensino da Educação Artística às 5 as e $6^{\mathrm{a} s}$ séries, o que viria a ser mantido, na prática, até o ano de 1999, gerando grande tensão entre os professores da disciplina. Em resposta, estes encaminharam à direção, aos chefes de Departamentos e colegas do CP II uma carta/projeto na qual solicitam a retomada da disciplina de Educação Artística nas $7 \underline{a}$ s e $8^{\text {ás }}$ séries, objetivando a coerência e a plenitude de seus projetos (COLÉGIO PEDRO II, 1985). As preocupações dos professores expressas 
nessa carta prenunciavam caminhos que o ensino da arte iria percorrer, no campo teórico, nos anos seguintes, e os problemas que assumiriam proporções muito maiores para o ensino da arte, tanto internamente, quanto em âmbito Nacional.

Segundo Barbosa (2005), o ano de 1986 foi especialmente danoso para o ensino da arte no Brasil, com a proposta de sua extinção, durante um Encontro de Secretários de Educação no Rio Grande do Sul, aprovada pela maioria dos Secretários presentes. Nesse mesmo ano, o Conselho Federal de Educação aprovaria a reformulação para o núcleo

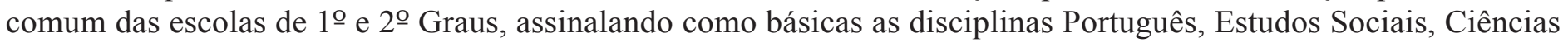
e Matemática, eliminando a área de Comunicação e Expressão, à qual pertencia Educação Artística. Esta disciplina passou a constar em apenas um parágrafo em que se afirmou que o ensino de Educação Artística também era exigido no currículo, providência insuficiente para evitar a eliminação do ensino da arte pela grande maioria das escolas privadas.

Tais condições perduraram e levaram a um esforço contínuo, por parte dos professores de arte do CP II, para a manutenção do ensino de sua disciplina nesse educandário. A possibilidade da retirada da disciplina da grade curricular da 6 $6^{\underline{a}}$ série em 1993, permanecendo apenas na 5aa série, provocou alto nível de inquietação. Inconformados, os professores elaboraram um documento dirigido ao chefe do Departamento de Desenho e Educação Artística, solicitando a permanência da disciplina na $6^{\underline{a}}$ série e, se possível, o retorno às $7^{\text {ạs }}$ e $8^{\underline{a} s}$ séries (COLÉGIO PEDRO II, 1993). A retomada dos espaços na matriz curricular significava a possibilidade de sobrevivência da disciplina e a manutenção de iniciativas como o curso de arte para as turmas de informática do $1^{\circ}$ ano do $2^{\circ}$ Grau da Unidade São Cristóvão III, únicas turmas desse nível que recebiam aulas regulares de arte.

Essa luta dos professores de Educação Artística do CP II pela permanência de sua disciplina nos programas aconteceu pelas mesmas razões e ao mesmo tempo em que outra, no campo político, se desenrolava em âmbito Nacional. Barbosa (2008) relata a batalha iniciada pelos arte-educadores em 1989, objetivando a manutenção da obrigatoriedade da arte na futura Lei de Diretrizes e Bases da Educação Nacional, confrontando uma resistência formada por educadores, técnicos do MEC e políticos que não viam a necessidade deste ensino ou argumentavam que o currículo necessitava ser recuperado por meio de conteúdos, considerando que a arte, por não possuí-los, deveria ficar de fora.

A ameaça da extinção da obrigatoriedade do ensino da arte, condição introduzida pela Lei 5.692/1971, era clara e teve entre seus propositores figuras de vulto da educação e da política. Como em qualquer confronto, aconteceram gestões políticas, reviravoltas, discussões e debates no Congresso Nacional, até as vésperas da votação da Lei no Senado, culminando com o êxito dos educadores que defendiam o ensino da arte e a inclusão da sua obrigatoriedade na Lei de Diretrizes e Bases da Educação Nacional, Lei 9.394, promulgada em 1996 (BARBOSA, 2008). 
Consideramos que o problema enfrentado pelo ensino escolar da arte no Brasil apresentava, naquele momento, componentes semelhantes aos da situação que levara, nos Estados Unidos, na virada dos anos 1950 para 1960, à formulação do conceito de educação artística centrada como disciplina e posteriormente ao sistema denominado Discipline-Based Art Education (DBAE). Segundo Eisner (1997), os arte-educadores norte-americanos haviam compreendido que a legitimidade do ensino escolar da arte dependeria da sua transformação em uma disciplina, o que exigia a inclusão de um corpo teórico. A história da arte, a estética e a crítica foram as vias encontradas para solucionar o problema imposto pela definição de disciplina fornecida pela ciência. No Brasil, uma das críticas em relação à permanência do ensino escolar da arte era baseada exatamente na suposição de que a arte não possuiria conteúdos, o que remetia à ideia de que seria uma prática ou atividade e revelava o desconhecimento da evolução conceitual pela qual vinha passando este ensino em âmbito nacional e internacional.

A vitória política e pedagógica dos professores de arte fica registrada, no âmbito do CP II, no PGE de 1996, o último da série, no próprio ano da promulgação da Lei de Diretrizes e Bases da Educação Nacional. Nele estão os novos programas de Educação Artística, com a fundamentação teórica e as orientações metodológicas que aprofundavam os conceitos presentes nos PGEs anteriores, em uma antecipação dos PCN de 1997.

O êxito dos professores de arte do CP II fica consubstanciado na adoção, pelo PGE, dos parâmetros que vinham sendo debatidos e utilizados progressivamente por eles, desde os finais dos anos 1970, alinhados com propostas da professora Ana Mae Barbosa. Os documentos relacionados com o ensino da arte no CP II mostram como este processo vinha se desenrolando há anos na instituição, ganhando vida nas pessoas das professoras que haviam realizado a transição de Trabalhos Manuais para Educação Artística.

No presente, sob a denominação Artes Visuais e desde o ano de 1971, quando passou a chamar-se Educação Artística com a reforma instituída pela Lei no 5.692/71, o ensino da arte é obrigatório nas escolas, devendo ser ministrado por professores com formação específica de nível superior. Entretanto, diferenças nas condições práticas, considerando as escolas públicas dos três níveis de administração, as escolas privadas e a diversidade regional, criaram discrepâncias quanto à ênfase e os métodos. Embora a LDB de 1996 tenha mantido a obrigatoriedade da presença da arte nos programas e dado a nota da relevância desta disciplina, o que foi consubstanciado pelos PCN de 1997, ainda são encontradas manifestações pedagógicas que caracterizaram períodos, ideologias e metodologias passados, com a manutenção de preconceitos típicos de outras eras. Mesmo em um grande centro urbano como o Rio de Janeiro, que já foi capital do país e, portanto, sede dos debates sobre a educação nacional por extenso período, é possível encontrar escolas nas quais a presença da disciplina hoje denominada Artes Visuais é pequena ou praticamente inexistente, permanecendo em um canto da matriz curricular, com o objetivo apenas de atender às exigências legais. Também são frequentes os questionamentos sobre a utilidade dessa disciplina sua manutenção como uma disciplina formal. 
Os PCN-Arte inspiram-se na Abordagem ou Proposta Triangular, formulada por Ana Mae Barbosa, na qual estão privilegiadas as ações básicas de leitura de obra de arte, contextualização histórica e fazer artístico. Os PCN enfatizam o uso da imagem na sala de aula e aprofundam a questão da filosofia de ensino e sua metodologia, mas sua implantação ainda é um desafio (BRASIL, 2000).

\section{Considerações finais}

A relevância do resgate da memória do ensino da arte em uma instituição como o CP II, cujo porte, tradição e longevidade a posicionam como uma das mais consistentes iniciativas no campo da educação brasileira foi a motivação principal para a realização deste trabalho. O interesse pela influência que o pensamento educacional em arte teve na formulação das Leis que regeram o ensino dessa disciplina no CP II, desde a sua instituição até a atualidade, foi outro fator para a pesquisa sobre os 175 anos dessa história, associado à sua condição de parâmetro mantida até o final dos anos 1950, para as demais escolas secundárias do país.

O material coletado permitiu compreender que o ensino da arte sempre foi objeto da atenção dos formuladores das políticas educacionais, tanto em âmbito nacional quanto internacional, gerando debates ou mesmo de embates, muitas vezes intensos. De fato, os legisladores brasileiros foram influenciados pelas tendências que regeram este ensino desde os primeiros momentos da sua existência, na época em que foram criadas as primeiras escolas secundárias no mundo.

$\mathrm{O}$ ensino da arte teve no desenho a sua primeira denominação, no CP II, como resultado do fenômeno da industrialização pelo qual passavam as nações mais desenvolvidas. As fontes consultadas mostram que os legisladores brasileiros tinham conhecimento das propostas europeias e norte-americanas e desejavam os benefícios que o ensino do desenho poderia trazer para o início do processo de industrialização no Brasil. Outra preocupação naquele momento dizia respeito à necessidade de modificar a aversão ao trabalho manual, arraigada em uma sociedade que ainda praticava a escravidão.

No Brasil, as políticas educacionais dos tempos do ensino da arte como desenho tiveram no liberalismo e no positivismo as principais fontes das propostas que inclúam, de um lado, a ideia da preparação para o trabalho e, de outro, a melhora do povo através da exatidão da matemática e da geometria. O CP II teve em seus quadros professores que faziam parte dessas correntes do pensamento educacional, com algumas figuras notórias e influentes, ligadas à Academia de Belas Artes e ao Liceu de Artes e Ofícios, que compreendiam as implicações e as aplicações dos modernos conceitos, participavam do debate no campo político e propunham soluções. A força dessas ideias relacionados com o ensino da arte como desenho, associada ao bem estruturado corpo docente do CP II assegurou a presença dessa disciplina na matriz curricular por 104 anos. 
A primeira mudança de denominação no ensino escolar da arte no contexto brasileiro acontece em 1942, durante o Estado Novo, fator que explica, em parte, a escolha dos Trabalhos Manuais para o ensino da disciplina no secundário, visto que naquele momento se desenvolviam os movimentos Escola Nova e Livre Expressão Artística, de caráter progressista, naturalmente combatidos pelo novo regime político de cunho fascista. A Livre Expressão não teve influência nos programas do CP II, voltados integralmente para o ensino dos Trabalhos Manuais, que objetivava a educação da mente por meio do treinamento manual. Associado ao ensino de Economia Doméstica, teve também o sentido de atender à crescente demanda por educação para as meninas.

Os professores que lecionaram Trabalhos Manuais e Economia Doméstica foram formados pelas Escolas Normais que apresentavam este ensino já nos finais do século XIX. Desempenharam relevante papel na manutenção do ensino da arte na vigência dessa denominação, fazendo frente ao renitente preconceito contra a atividade manual, considerada inferior. Esses mesmos professores viriam a ser exigidos pelas circunstâncias em outras ocasiões de destaque no ensino escolar da arte no Brasil e no CP II, com as dificuldades impostas pelo início do ensino da arte como Educação Artística e posteriormente pela ameaça da extinção do ensino escolar da arte.

Após 1964, a compreensão sobre as necessidades de um sistema educacional que já não respondia às demandas da população e a necessidade de mão de obra para a indústria levaram a uma reforma educacional de sentido profissionalizante, planejada pelos representantes do regime militar, em colaboração com educadores americanos. Essa reforma foi determinada pela Lei 5.692/1971 e, pela primeira vez, tornou o ensino da arte obrigatório nas escolas, com a denominação Educação Artística e como uma atividade, o que significava que não era considerada uma disciplina com todas as suas características formais. Nesse momento, os professores tiveram de atuar em condições de reduzidas orientações programáticas e de modificação dos parâmetros formativos, com a criação das primeiras graduações em Educação Artística, que introduziram a chamada polivalência, condição que nunca existiu no CP II.

A reação dos professores do CPII, a rigor professoras, aconteceu por meio da busca por formação teórica e treinamento, este obtido nas Escolinhas de Arte do Brasil e em cursos ministrados por artistas. Este movimento levou à formulação de conceitos para o ensino da arte, fenômeno que envolveu educadores da arte de todo o país e que culminou, sob a influência do pensamento oriundo de educadores norte-americanos progressistas, nas propostas relacionadas à instituição da arte como uma disciplina.

A abertura democrática trouxe novos debates que expressavam o desejo de reformular a educação nacional, modificando a estrutura criada pela ditadura. Nesse momento o ensino da arte esteve gravemente ameaçado de extinção, sob o argumento de que a matriz curricular deveria ser preservada para as disciplinas formais. Novamente os professores de arte do CP II assumem a luta pela preservação de sua disciplina, lutando interna e externamente para manter sua posição na matriz curricular. Essa luta teve êxito no campo político, expresso pela manutenção da 
obrigatoriedade do ensino da arte na LDB de 1996. No campo pedagógico, a vitória aparece com a inclusão dos parâmetros por eles elaborados para o ensino da arte, em uma evolução iniciada nos finais dos anos 1970. Este ensino encontra-se hoje investido das características formais de disciplina, regido pelos Parâmetros Curriculares Nacionais-Arte.

\section{Referências}

BARBOSA, Ana Mae. Arte educação no Brasil. São Paulo: Perspectiva, 2005.

. A imagem no ensino da arte: anos oitenta e novos tempos. São Paulo. Perspectiva, 2005a.

. Arte-Educação: conflitos/acertos. SP: Max Limonad, 1988.

p. $1-26$. Entre memória e história. In: BARBOSA, Ana Mae (Org.). Ensino da arte: memória e história. São Paulo: Perspectiva, 2008.

BRASIL. Lei no 9.394, de 20 de dezembro de 1996. Estabelece as Diretrizes e Bases da Educação Nacional. Casa Civil, Subchefia para assuntos jurídicos. Disponível em: <http://www.planalto.gov.br/ccivil/LEIS/L9394.htm>. Acesso em: 18 maio 2012.

BRASIL. Ministério da Educação e Cultura. Decreto-Lei 4.244, de 9 de abril de 1942. Lei Orgânica do Ensino Secundário e Legislação Complementar. Rio de Janeiro: Imprensa Nacional, 1955.

BRASIL. Ministério da Educação e Cultura. Lei no 5.692. Lei de Diretrizes e Bases da Educação. Brasília, 1971. Disponível em: <http:// www6.senado.gov.br/legislacao/ListaPublicacoes.action?id=102368>. Acesso em 18 maio 2012.

BRASIL. Portaria Ministerial no 614, de 10 de maio de 1951.

BRASIL. Portaria Ministerial no 557 de 1945. Diário Oficial da União, seção 1.

BRASIL. Parecer no 853 de novembro de 1971. Conselho Federal de Educação. Câmara de Ensino de 1ํe e o Graus. Integrado na Lei 5.692/71. Novembro de 1971 .

BRASIL. Ministério da Educação e Cultura. Departamento de Ensino Médio. Plano Global de Implantação Progressiva das Habilidades Básicas no Colégio Pedro II. 2. ed. revisada. Brasília, DF, 1977.

BRASIL. Parâmetros Curriculares Nacionais: Introdução aos Parâmetros Curriculares Nacionais. Rio de Janeiro: DP\&A, 2000.

CARVAlHo E SILVA, Maria do Carmo Potsch de. O ensino da arte no Colégio Pedro II: políticas e práticas. Dissertação (Mestrado em Educação) - Programa de Pós-Graduação em Educação, Universidade Estácio de Sá (PPGE/UNESA). Rio de Janeiro, 2013.

COLÉGIO PEDRO II. Programa de Educação Artística - Artes Plásticas. $1^{\circ}$ e $2^{\circ}$ Graus. Externato. Unidade Bernardo de Vasconcellos, Seção Tijuca, 1979. (Datilografado).

Plano Geral de Ensino 1981.

Plano Geral de Ensino 1985. 
COLÉGIO PEDRO II. Relatório dos Professores de Educação Artística a respeito da reciclagem de 1993. (Datilografado).

DÓRIA, Escragnolle. Memória histórica do Colégio de Pedro Segundo. Brasília: Inep, 1997.

EFLAND, Arthur. A history of art education. New York: Teachers College. Columbia University, 1990.

EISNER, Elliot. Estrutura e mágica no ensino de Arte. In: BARBOSA, Ana Mae (Org.). Arte-Educação: leitura no subsolo. São Paulo: Cortez, 1997. p. 77-92.

GOMBRICH, Ernest. A história da arte. 16. ed. Rio de Janeiro: LTC Editora, 1999.

PAREYSON, Luigi. Os problemas da estética. São Paulo. Martins Fontes, 2001.

ROMANELLI, Otaíza de Oliveira. História da educação no Brasil: 1930-1973. 36. ed. Petrópolis: Vozes, 2010.

ROSA, Maria Cristina de. A formação do professor de arte: diversidade e complexidade pedagógica. Florianópolis: Insular, 2005.

SEGISMUNDO, Fernando. Trabalhos manuais no currículo secundário. Separata do Anuário do Colégio Pedro II, v. IX. Rio de Jnaeiro, 1939.

XAVIER, Maria Elisabete. Historia da educação: a escola no Brasil. São Paulo: FTD, 1994.

Recebido em: fevereiro/2016

Aceito em: maio/2016

Endereço para correspondência:

Maria do Carmo Potsch de Carvalho e Silva

Av. Presidente Vargas 642, 22ㅇ andar - Centro

20071-001 Rio de Janeiro, RJ, Brasil

<kkpotsch@globo.com> 